\title{
Characterization of Beryllium Copper Intermetallic Phases at a Beryllium Braze Interface by EPMA and TEM
}

\author{
P.A. Papin, R.D. Field, and D.A. Javernick \\ Los Alamos National Laboratory, Material Science Technology Division, Mail Stop G770, \\ Los Alamos, NM 87545, USA
}

Beryllium metal in contact with liquid Cusil braze alloy (a copper silver eutectic) forms intermetallic layers of beryllium and copper; the composition and thickness of these layers varies with brazing temperature and subsequent heat treatments [1-2]. Positive identification of the $\mathrm{Be}$ and $\mathrm{Cu}$ phases formed was vital to optimizing parameters to produce a strong joint. While TEM can resolve and differentiate these layers, accomplishing this goal on an electron microprobe was advantageous.

Electron probe microanalysis (EPMA) was successful at discriminating between $\mathrm{CuBe}$ and $\mathrm{CuBe}_{2}$ layers. The quantitative elemental profiles obtained across the beryllium braze interface were found to be in agreement with diffraction data generated on a TEM. Site-specific TEM foils for the area analyzed on the microprobe were fabricated using focused ion beam (FIB) instrumentation.

Samples were prepared using standard metallographic techniques to view the layers in cross section. Microprobe analyses were performed on a JEOL 840 with a Geller Microscopy Analysis system. The standards used were an elemental copper sample and a 50:50 beryllium nickel alloy, previously fabricated and characterized on site. It was presupposed that matrix corrections for nickel would be close to those for copper. A LiF crystal was used for $\mathrm{Cu}$ and a LBED crystal for Be. Silver did not have any appreciable solubility in any of the other phases present and appeared as segregated islands away from the area of interest. Samples and standards were run without carbon coatings. The LoveScott I method was used for ZAF corrections after comparison with other methods. Figures 1a and $1 \mathrm{~b}$ show the quantitative data obtained by EMPA across the beryllium braze. This sample was subjected to a longer heat treatment at higher temperature compared to the standard braze cycle, resulting in layers of increased thickness, from a few microns at $800 \mathrm{C}$ for 5 minutes to over 10 microns thick at $870 \mathrm{C}$ for 30 minutes.

TEM specimens were made on a FEI Dual Beam 235. A residual carbon trace from the EMPA line scan served as an indicator for the site-specific TEM foils, as shown in Figures 2 and 3. Diffraction data were taken from representative grains in each layer. In each case, data from three zone axes were analyzed; d-spacings, interplanar and interzonal angles all yielded excellent agreement to the calculated values. The layer adjacent to the Be metal gave diffraction data consistent with the $\mathrm{C} 15$ Laves phase $\mathrm{CuBe}_{2}(\mathrm{Fd} \overline{3} \mathrm{~m}, \mathrm{a}=0.598 \mathrm{~nm})$. The next layer was identified from diffraction data to be the $\mathrm{B} 2$ phase $\mathrm{CuBe}(\mathrm{Pm} \overline{3} \mathrm{~m}, \mathrm{a}=0.269 \mathrm{~nm})$. Figure 4 shows the $2^{\text {nd }}$ TEM foil with both phases identified. The order of the phases, with the Be rich phase adjoining the Be base metal, is consistent with the microprobe data and is expected for the case of liquid Cusil alloy in contact with Be. It is also interesting to note that the microprobe data reveal compositional gradients in the $\mathrm{CuBe}_{2}$ phase, with higher $\mathrm{Be}$ content next to the $\mathrm{Be}$ and higher $\mathrm{Cu}$ content next to the $\mathrm{CuBe}$, consistent with the wide solubility range and low diffusivity of this phase. The $\mathrm{CuBe}$ phase has a much smaller solubility range and higher diffusivity, reflected in the more homogeneous composition in the microprobe data. 
References

[1] T.F. Drouillard, Materials Evaluation, 11 (1992) 1349.

[2]T.G. Glenn et al, Welding Journal, 61 (1982) 334.
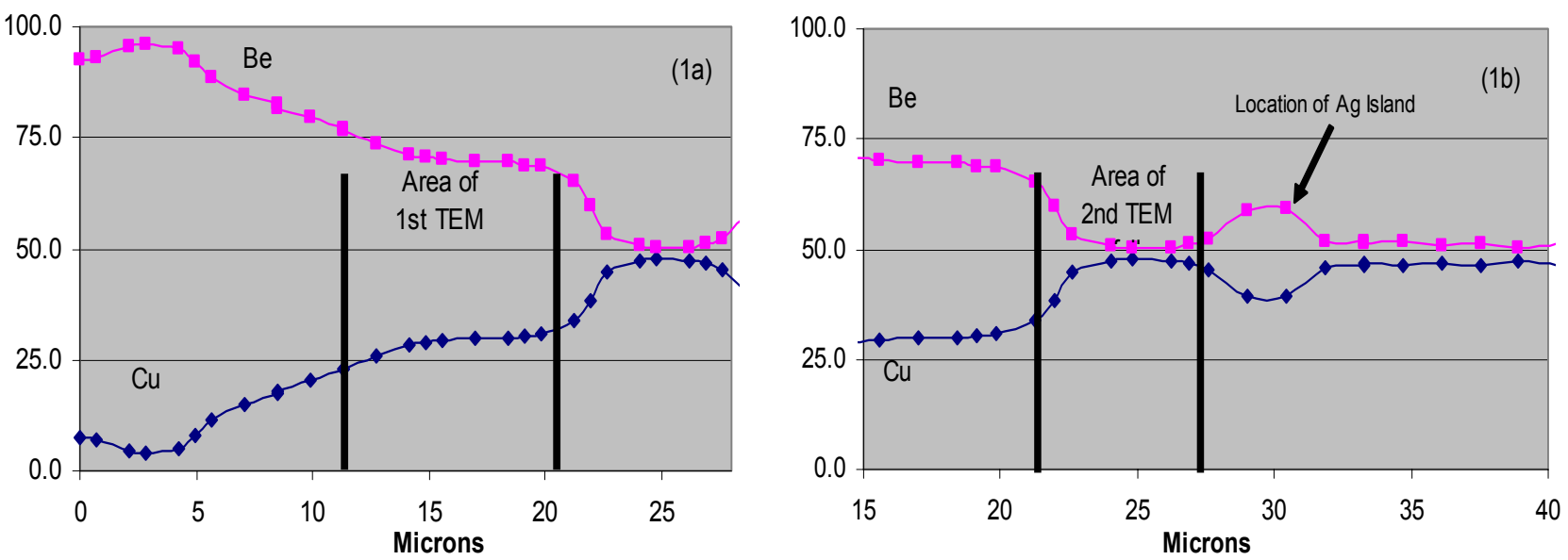

Fig. 1. Composition in Atomic Percent of Layers at Beryllium Braze Interface

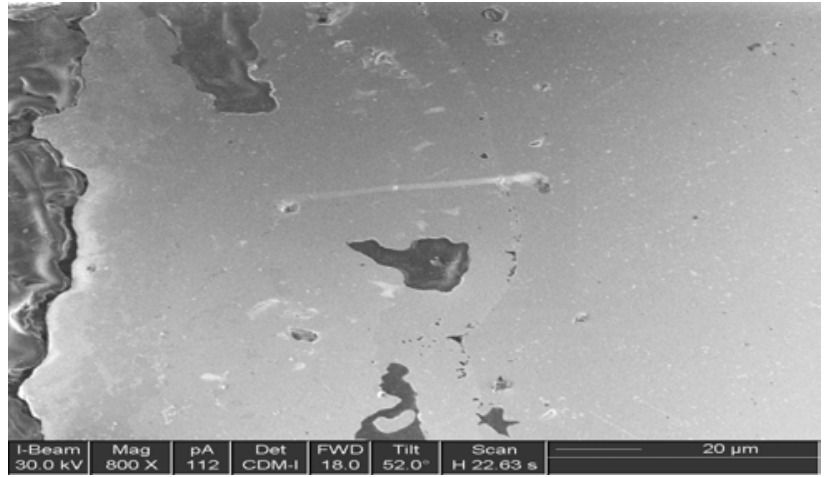

Fig. 2. Carbon Trace from EPMA

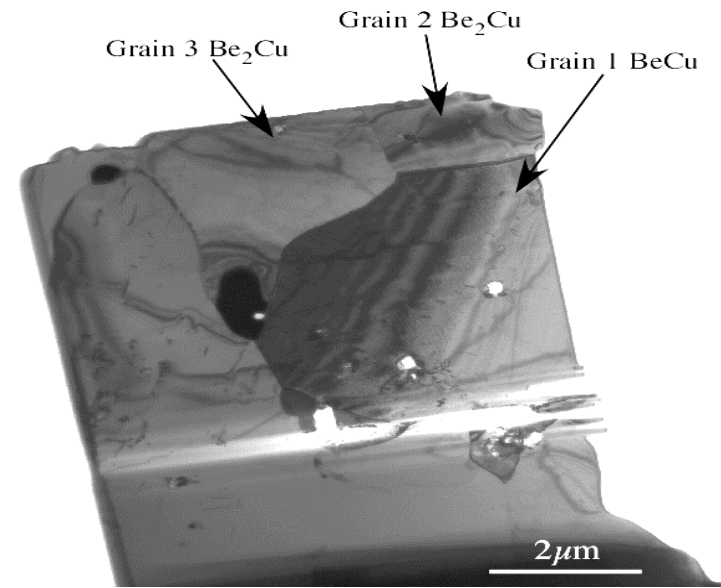

Fig. 4. 2nd TEM Specimen

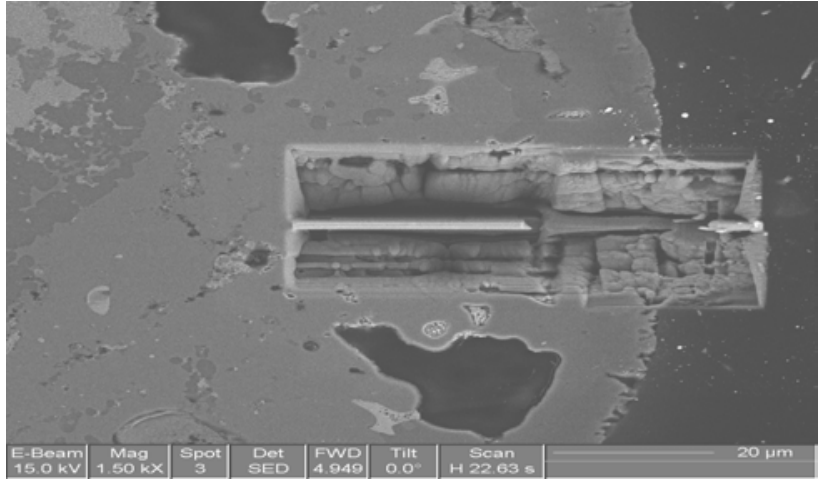

Fig. 3. Site Specific TEM Specimens 